\title{
Selection of optimal solution heat treatment of the casting cylinder heads
}

\author{
Eva Tillová ${ }^{1, *}$, Mária Chalupová ${ }^{1}$, Lenka Kuchariková $^{1}$, Juraj $_{\text {Belan }}{ }^{1}$, Denisa Závodská ${ }^{1}$ \\ ${ }^{1}$ University of Žilina, Department of Materials Engineering, Univerzitná 8215/1, 01026 Žilina, \\ Slovak Republic
}

\begin{abstract}
The effect of solution treatment on mechanical properties (UTS, elongation, Brinell hardness) and microstructure (Si-morphology and Si-size) of an aluminium alloy (A356) used for casting cylinder heads was studied. The tests were carried out with specimens machined from the bulkheads of V8 engine blocks cast by the low pressure process. The samples were tested in as-cast and $\mathrm{T} 6$ heat treating conditions (solution heat treatment at $530^{\circ} \mathrm{C}$ with different time $-2,3,4,5,6,7$ hours, quenching in water at $20^{\circ} \mathrm{C}$ and precipitation hardened for 4 hour at $160^{\circ} \mathrm{C}$ ). The results show that used heat treatment improves mechanical properties of the cylinder head casts. Tensile strength and hardness of specimens increase with solution treatment time. The hardness is a reflection of solution strengthening and silicon particle distribution in matrix. Solution temperature $530^{\circ} \mathrm{C}$ and 5 hours solution time is appropriate to obtain better morphology and distribution of $\mathrm{Si}$ particles in microstructure. Prolonged solution treatment (more than 5 hours) leads to a coarsening of the Si particles, while the numerical Si density decreases. As the particle density decreases, a fewer number of sites are available for crack nucleation, and hence, the fracture properties are improved. The data obtained from this study will be used to improve process control, and to help the selection of heat treatment of the casting for future products.
\end{abstract}

Keywords: Al-Si cast alloy, mechanical properties, solution treatment

\section{Introduction}

The cylinder head is an integral component of internal combustion engines. It conveys air and gasoline to the combustion chamber and serves as a cover for the cylinders. The main function of the cylinder head is to help the head gasket seal the cylinders properly so that they are able to build enough compression for engine operation. In the vast majority of four stroke engines, the cylinder head mounts the entire valve gear and provides the basic framework for housing the gas-exchange valves as well as the spark plugs and injectors. It also supports the different parts of cooling system [1].

The cylinder head must be strong and rigid to distribute the gas forces acting on the head as uniformly as possible through the engine block. The combustion gas, the coolant and the lubricating oil flow independently in the cylinder head and follow complex three

* Corresponding author: eva.tillova@fstroj.uniza.sk

Reviewers: Darina Ondrušová, Mariana Pajtášová 
dimensional routes. Thus cylinder heads are generally produced by gravity or low-pressure die casting. In Europe, grey cast iron cylinder heads have been almost completely replaced by cast aluminium alloys during the past 20 years. Aluminium has the advantages of light weight, high thermal conductivity, and ease of production to close tolerances. Depending on the engine type, the introduction of an aluminium cylinder block results in a weight reduction of 10 to $20 \mathrm{~kg}$ (i.e. at least $50 \%$ ) [1-2]. An important fact is that weight reduction has a ripple effect on fuel efficiency. For example, weight reduction enables the manufacture to develop the same vehicle performance with a smaller engine, and such a smaller engine enables the use of a smaller transmission and a smaller fuel tank. With this ripple effect, it is estimated that $10 \%$ of vehicle weight reduction results in $8-10 \%$ of fuel economy improvement [3].

Aluminium cast alloys used in the production of such complex cast parts as engine blocks or cylinder heads must meet a combination of requirements which include low cost, excellent castability, low hot tearing tendency, good machinability, moderate strength at elevated temperatures and resistance to fatigue, i.e. high fatigue strength at elevated temperatures. As a result of the permanent increase of combustion pressures and temperatures, the potential of the common aluminium cylinder head alloys is almost fully exploited. In order to satisfy all the product requirements, optimised casting alloys and a proper control of the as-cast microstructure by the application of sophisticated casting processes are generally necessary. The applied aluminium alloys have to offer sufficient strength and hardness at room temperature for machining and assembly. Furthermore, high strength at elevated temperatures (up to $250^{\circ} \mathrm{C}$ ) is crucial to ensure that the engine blockcylinder head assembly can withstand the combustion forces and the forces resulting from thermal expansion and contraction during service cycles without losing tightness of the cylinder head gasket. Creep strength is required in particular for the head gasket area $[1,4,5]$.

To improve strength and creep properties, generally, alloying elements such as $\mathrm{Mg}$ and $\mathrm{Cu}$ are added [6]. On the other hand all alloying elements which dissolve in the $\alpha$-matrix or which will reduce the amount of $\alpha$-dendrites will decrease the heat conductivity. Ductility can be increased by low iron contents which on the other hand increases the price for the alloy. Further contribution to higher ductility will be given by modification of the AlSieutectic by means of $\mathrm{Na}$ or $\mathrm{Sr}$ [7]. Unfortunately, the addition of the modifier elements is often associated with increased porosity, possibly through altered feeding efficiency or increased risk to gas pick-up of the aluminium melt [8-9].

The best combinations of strength and ductility are offered by casting alloys with low iron content such as AlSi7Mg0.3 (A356). Therefore, in the past, most cylinder heads were made from primary aluminium alloys. But also alloys which can be produced using recycled aluminium (i.e. with a slightly increased impurity content) still provide sufficient ductility [1]. The mechanical properties of an Al-Si cast alloy for engine blocks and cylinder heads are mainly determined by its cast structure and the microstructural characteristics such as the grain size, dendrite arm spacing (DAS) [10], the size, shape and distribution of the eutectic silicon particles [6, 11-12], as well as the morphologies and amounts of intermetallic phases present [13].

Cylinder heads are usually applied in the T6 condition. Heat treatment influences the resultant mechanical properties [14-24]. The T6 heat treatment comprises three stages $[19,20]$ :

- Solution heat-treating at relatively high temperature is required to activate diffusion mechanisms, first, to dissolve Mg-rich phases formed during solidification and, then, to homogenize the alloying elements, such as $\mathrm{Mg}$ and $\mathrm{Si}$, so as to achieve an elevated yield stress subsequent ageing [19]. Further, the solution heat treatment changes the 
morphology of eutectic Si from polyhedral or fibrous morphology in the modified alloys, to globular structure [11-12, 15-17].

- Quenching is usually carried out to room temperature to obtain a supersaturated solid solution of solute atoms and vacancies, in order to achieve an elevated strengthening subsequent ageing [19]. The most rapid quench rate gives the best mechanical properties, but it can also cause unacceptable amounts of distortion or cracking in components. Thus, parts of complex shape, often with both thin and thick sections, are commonly quenched in a medium that provides a slower cooling. This hardening medium can be hot water, an aqueous solution of polyalkylated glycol, or other fluid medium such as forced air or mist [20,22].

- Artificial ageing consists of further heating the casting at relatively low temperatures $\left(120-210^{\circ} \mathrm{C}\right)$ and it is during this stage that the precipitation of dissolved elements occurs [25]. These precipitates are responsible for the strengthening of the material. In AlSiMg cast alloys, the decomposition of the supersaturated solution begins with the clustering of Si atoms. This clustering leads to the formation of coherent spherical GP zones, consisting of an enrichment of $\mathrm{Mg}$ and $\mathrm{Si}$ atoms that elongate along the cube matrix direction to develop into a needle shape coherent $\beta^{\prime \prime}$ phase. With prolonged ageing, the needle shaped GP zones grow to form rods of an intermediate phase, $\beta^{\prime}$, which is semicoherent with the matrix. The final stable $\beta-\mathrm{Mg}_{2} \mathrm{Si}$ phase forms as an incoherent platelets on the $\alpha$-Al matrix and has ordered face centered - cubic structure [19].

The present study is part of a larger research project which was conducted to evaluate the heat treatment of an AlSi7Mg0.3 cast alloy used in the manufacture of engine blocks and cylinder heads. The study was conducted on as-cast and heat treated samples that were cut from the bulkheads of cylinder heads. The experiments were carried out in cooperation with the practice. The manufacturer required selection of optimal solution heat treatment, respectively shorter dissolution annealing times.

\section{Material and experimental procedure}

For the experimental work were used cylinder head castings OM 661 for Daewoo (Fig. 1) that were produced from the most popular AlSi7Mg0.3 (A356) alloy. Melt was grain refined with Tiboral 6 masteralloy. Modification was achieved with AlSr 90/10 masteralloy. The chemical composition (in wt. \%) of the melt prepared is shown in Table 1. Addition of $\mathrm{Sr}$ and $\mathrm{Na}$ can cause a transition of the eutectic silicon phase from coarse acicular flakes and plates (needles), which often act as crack initiators, to fine fibber's there consequently, improve the mechanical properties, especially the ductility.

Table 1. Chemical compositions of experimental material used in the present study (in wt. \%)

\begin{tabular}{|c|c|c|c|c|c|}
\hline $\mathbf{S i}$ & $\mathbf{M g}$ & $\mathbf{T i}$ & $\mathbf{F e}$ & $\mathbf{M n}$ & $\mathbf{C r}$ \\
\hline 6.96 & 0.356 & 0.125 & 0.108 & 0.007 & 0.0005 \\
\hline $\mathbf{N i}$ & $\mathbf{Z n}$ & $\mathbf{S r}$ & $\mathbf{C a}$ & $\mathbf{N a}$ & $\mathbf{A l}$ \\
\hline 0.0036 & 0.004 & 0.0343 & 0.0017 & 0.0005 & rest. \\
\hline
\end{tabular}

Experimental samples (Fig. 2) for microstructure observation and mechanical properties were cut from commercial automobile cylinder head castings (supplied from the manufacturer). The castings were in the as-cast and heat treated conditions. Standard heat treatment used for this type of experimental cylinder head in the foundry is solution heat treatment for 7 hours at $530^{\circ} \mathrm{C}$, quenching in water at $20^{\circ} \mathrm{C}$ and precipitation hardening for 
4 hour at $160^{\circ} \mathrm{C}$. The manufacturer required selection of optimal solution heat treatment, respectively shorter solution heat treatment times to achieve the required strength, hardness and ductility values.

Experimental castings (cylinder heads) were solution treated by different solution time $\left(2,3,4,5,6\right.$ and 7 hours) at $530^{\circ} \mathrm{C} \pm 5^{\circ} \mathrm{C}$, quenched in water at $20^{\circ} \mathrm{C} \pm 2{ }^{\circ} \mathrm{C}$ and precipitation hardened for 4 hour at $160{ }^{\circ} \mathrm{C} \pm 5^{\circ} \mathrm{C}$. The as-cast state specimens represent the 0 -hour aging time condition. Heat treatment was carried out by the manufacturer.

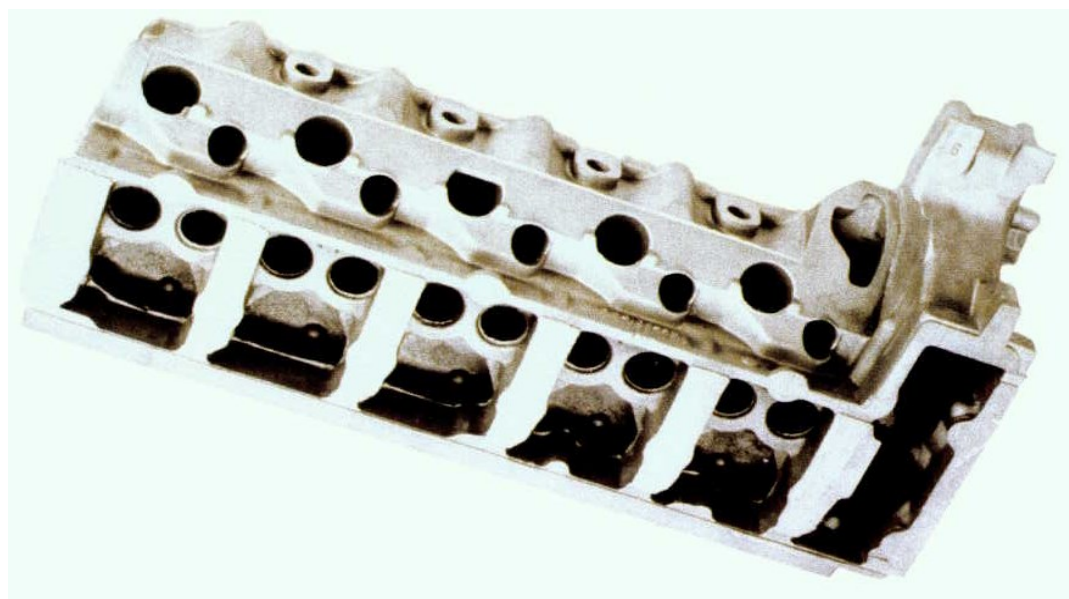

Fig. 1. The experimental cylinder head casting

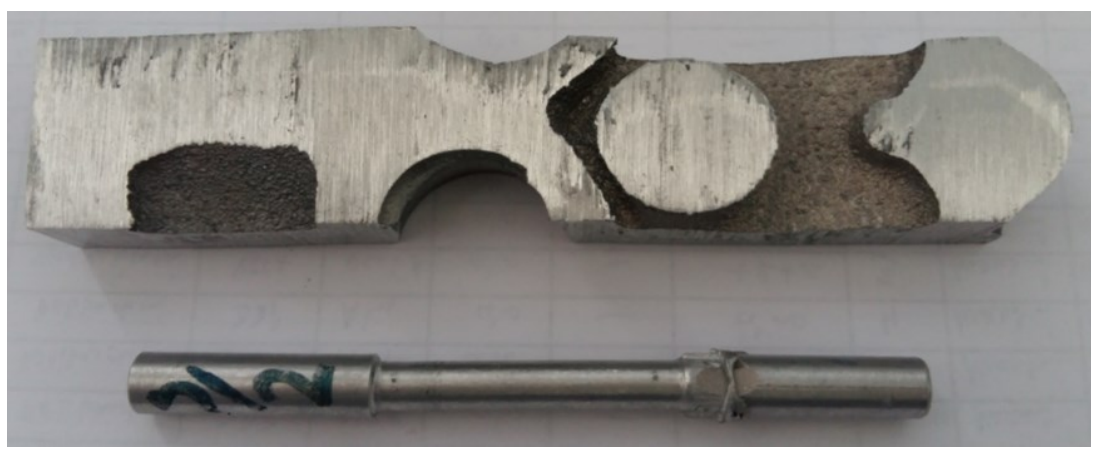

Fig. 2. Part of casting and sample for tensile test

Tensile test were carried out on a tensile machine ZDM 30 at room temperature following the STN EN ISO 6892-1 in as-cast state and after heat treatment; these specimens were of $14 \mathrm{~mm}$ in diameter by $120 \mathrm{~mm}$ in gauge length (Fig. 2). Values of ultimate tensile strength in dependence on heat treatment were determined by the average value of three test bars. Hardness measurement was performed by a Brinell hardness tester with the load of $250 \mathrm{kp}$, $5 \mathrm{~mm}$ diameter ball and the dwell time of $30 \mathrm{~s}$ according to standard STN EN ISO 6506-1. The Brinell hardness value at each state was obtained by the average of at least six measurements.

Metallographic samples were sectioned from the tensile test bars (after testing) and standard prepared for metallographic observations. A conventional grinding and polishing process, consisting of wet grinding on increasingly finer 500 and 1200 grade round $\mathrm{SiC}$ grinding papers (Struers TegraPol-15). The samples were then polished with $3 \mu \mathrm{m}$ diamond 
pastes followed by Struers Op-S. Subsequently, etching sample preparation was carried out in these steps: a) for observation in optical microscope: standardly etched by $0.5 \% \mathrm{HF}$. Thereafter the specimens were washed under running water, then ethanol, and dried; b) for observation in scanning electron microscope (SEM): standardly etched by $0.5 \% \mathrm{HF}$ or deep etched for $30 \mathrm{~s}$ in $\mathrm{HCl}$ solution $(36 \mathrm{ml} \mathrm{HCl}, 100 \mathrm{ml}$ distilled water) in order to reveal the three-dimensional morphology of the phases (eutectic silicon or intermetallic phases). Details of sample preparation are given in $[6,18]$.

The microstructures were immediately studied using an optical (Neophot 32) or scanning electron microscope VEGA LMU II. Chemical composition of phases were analysed by the energy dispersive X-ray spectroscopy (EDX analyser Brucker Quantax). Mapping of some specific areas of the polished sample surfaces was also carried out to show the distribution of alloying elements in the phases. The silicon particle characteristics (average Si particle area $\left(\mu \mathrm{m}^{2}\right)$ ) were measured using a NIS Elements 4.0 image analyser.

\section{Results and discussion}

\subsection{Microstructural evaluation}

This type of alloy is characterized by dendrite structure (Fig. 3a) with a homogeneous distribution of eutectic silicon. The as-cast microstructure of AlSi7Mg0.3 consists of $\alpha$ phase (Al-matrix), eutectic (mixture of eutectic silicon and $\alpha$-matrix) and various types of $\mathrm{Fe}-$ and $\mathrm{Mg}$ - rich intermetallic phases (Fig. 3b).
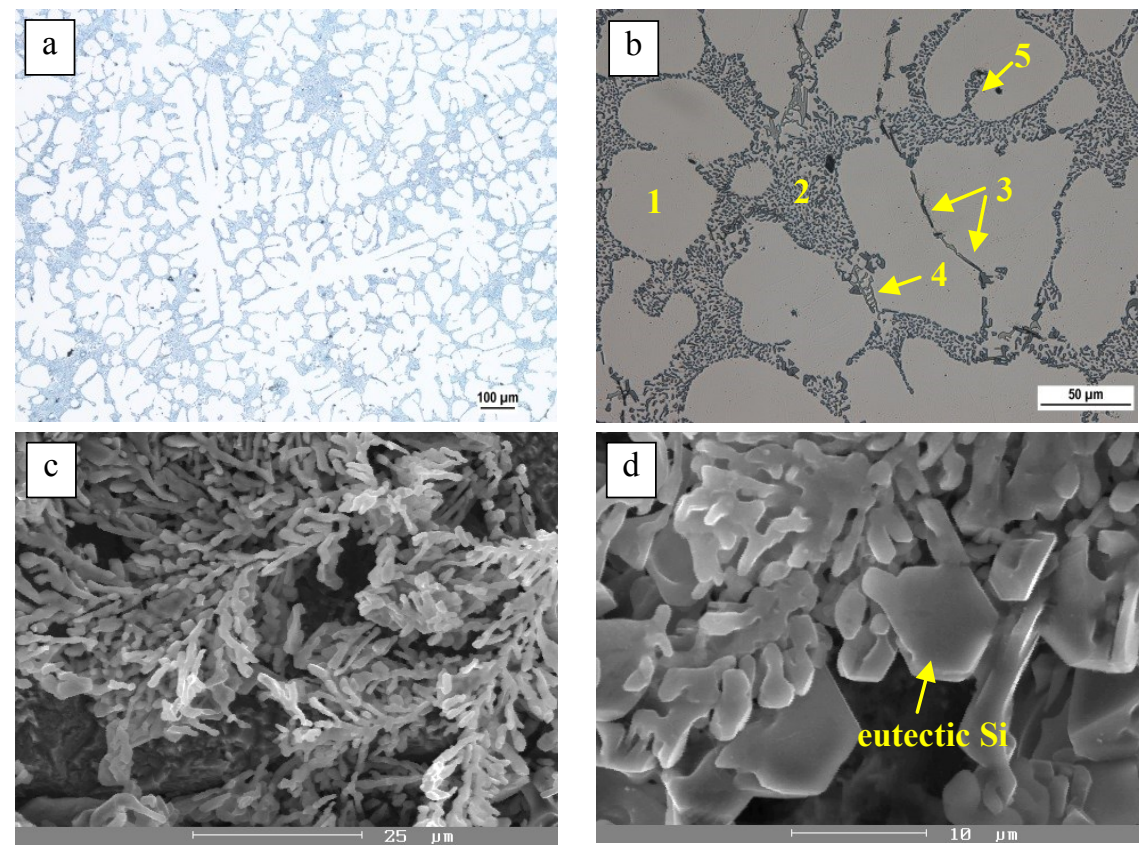

Fig. 3. Microstructure of cylinder head: a) as-cast state; b) phases (1-matrix; 2-eutectic; 3-needless $\mathrm{Al}_{5} \mathrm{FeSi}$; 4-compact skeleton-like $\left.\mathrm{Al}_{15}(\mathrm{FeMn})_{3} \mathrm{Si}_{2} ; 4-\mathrm{Mg}_{2} \mathrm{Si}\right)$;

c) morphology of eutectic Si (SEM); d) detail of eutectic Si-morphology (SEM)

By the addition of appropriate elements such as strontium in the liquid metal, it is possible to modify silicon morphological structure from lamellar to globular during the 
solidification. This modification treatment improves the mechanical properties of the Al-Si alloy by reducing the notching effect of needle shaped natural eutectic silicon $[6,9,18]$. The silicon appears as fibbers with a round cross-section (Fig. 3c). Fibbers grow as clusters from a single nucleating site. The 3-D form bars corresponds with metallographic sections, i.e. bunchy in the middle of the arrangement prevailing fine round bars and outwards, increased incidence of so called plate-like type with hexagonal shape (Fig. 3d).
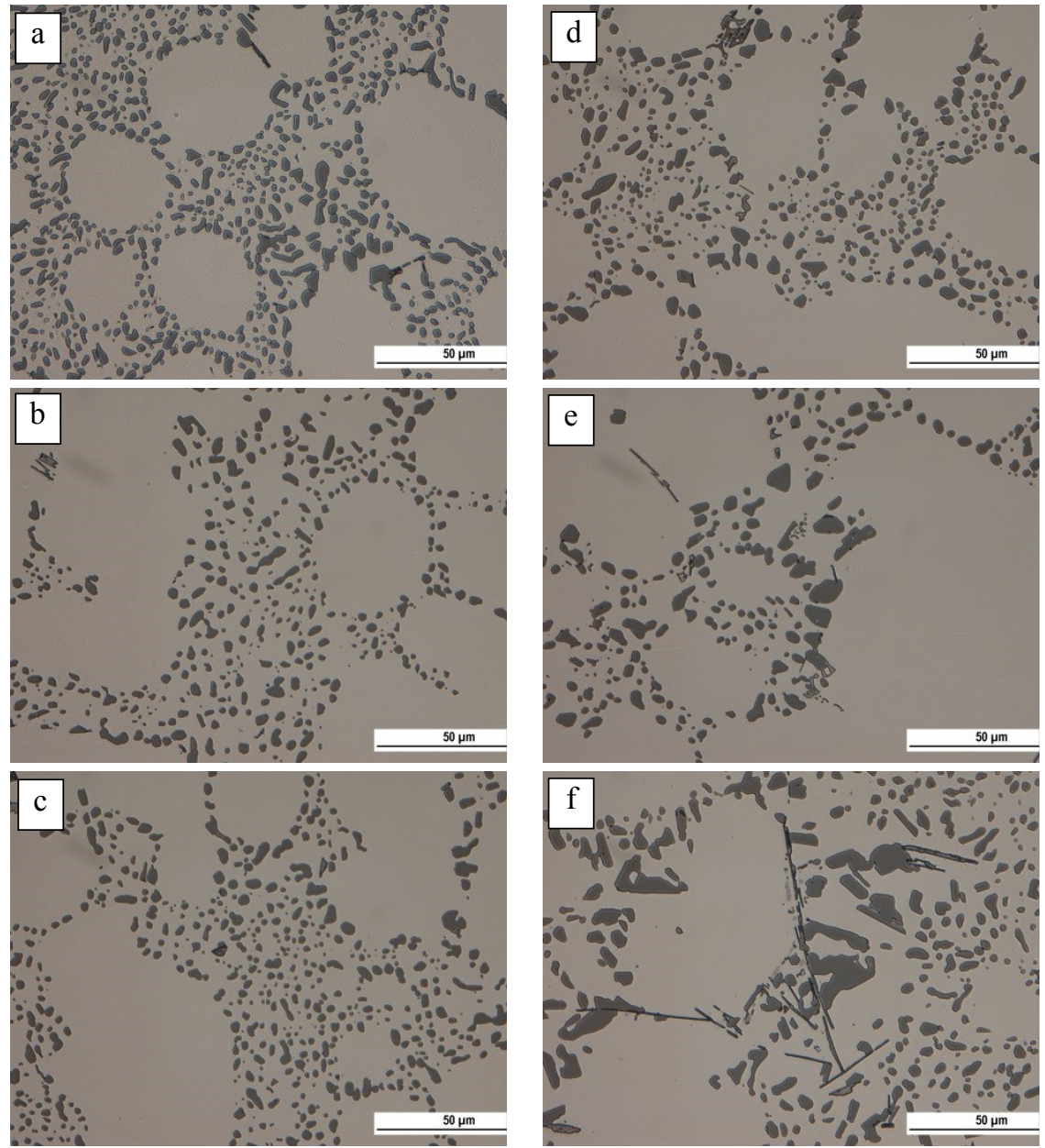

Fig. 4. Effect of solution treatment on microstructure of AlSi7Mg0.3 cast alloy,

a) 2 hours; b) 3 hours; c) 4 hours; d) 5 hours; e) 6 hours; f) 7 hours, etch. $0.5 \% \mathrm{HF}$

The effects of solution treatment time on microstructure and eutectic silicon morphology are shown in Fig. 4 and Fig. 5. Solution treatment causes a substantial degree of spheroidization and coarsening in modified eutectic phases. During the first 2 hours of solution treatment (Fig. 4a; Fig. 5a) Si particles gradually fragmented and rapidly spheroidized. Spheroidization process of the silicon through heat treatment takes place in two stages: fragmentation or dissolution of the eutectic fibbers/branches and spheroidization of the separated branches. The rate of spheroidization depends on the size of the fragmented segments.

Prolonged solution treatment leads to a significant coarsening of the $\mathrm{Si}$ particles (Fig. 4b-f, Fig. 5b-f). The former has the greatest effect on the time required to complete 
spheroidization and is strongly affected by the morphology of the Si particles. In Fig. 4e, Fig. 4f, Fig. 5e and Fig. 5f we can see that prolonged solution treatment time (more than 4 hours) leads to a coarsening of the Si particles, while the numerical Si density decreases. The spacing between the particles increased evidently too. It has been proved that structure containing large and elongated particles but small dislocation slip distances (within the dendrite cells) exhibited a high particle cracking rate and thus a low ductility [26]. Therefore, especially for unmodified A356 alloy, structure refinement by means of solution treatment for enough time is very important in improving the ductility.
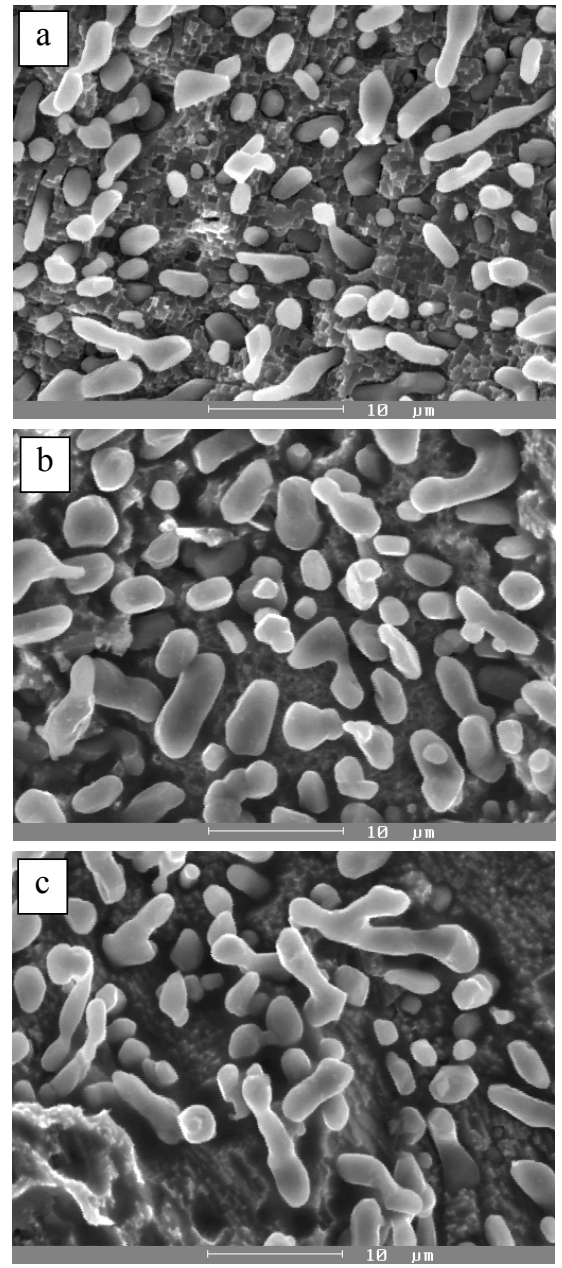
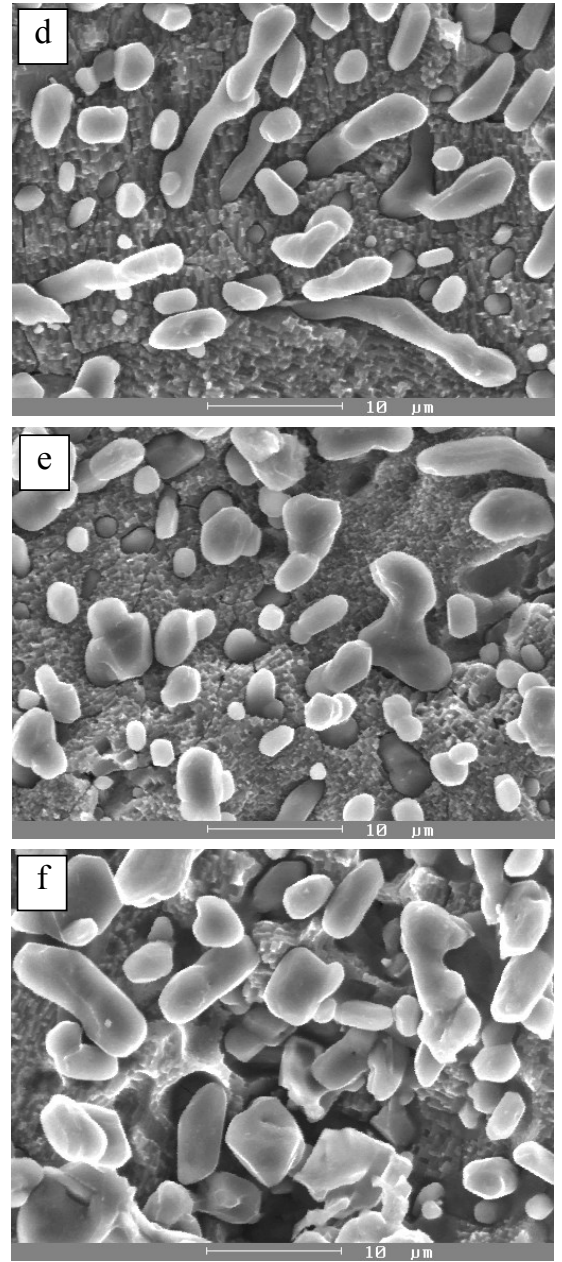

Fig. 5. Effect of solution treatment on morphology of eutectic Si (SEM), a) 2 hours; b) 3 hours; c) 4 hours; d) 5 hours; e) 6 hours; f) 7 hours, deep etch. $\mathrm{HCl}$

Fig. 6 shows the change in the average diameter of the silicon particles reflecting the particle round as a function of solution time at $530^{\circ} \mathrm{C}$. Due to the presence of modifier as $\mathrm{Sr}$ and $\mathrm{Na}$, the particles in the modified material are already fine and rounded. The average diameter of silicon particles increased rapidly within the first 2 hours at the solution temperature (from $2.14 \mu \mathrm{m}^{2}$ in as cast state to $3.9 \mu \mathrm{m}^{2}$ after 2 hours). Then they increased slowly with further increase in solution time $\left(3.95 \mu \mathrm{m}^{2}\right.$ after 3 hours; $4.18 \mu \mathrm{m}^{2}$ after 4 
hours). After a prolonged solution treatment of 5 hours at $530^{\circ} \mathrm{C}$, the average diameter of the silicon particles increased to $5.27 \mu \mathrm{m}^{2}$. These results are in agreement with [27-28].

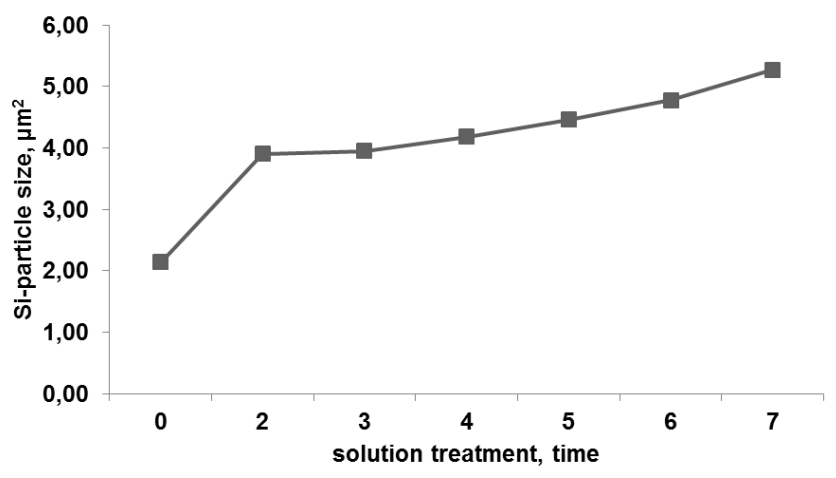

Fig. 6. Effect of solution treatment on Si-particle size

Fe-rich intermetallic phases and $\mathrm{Mg}_{2} \mathrm{Si}$ particles are also observed in the microstructure (Fig. 1b). Fe-rich phases are just like eutectic Si completely brittle [6, 13]. It is suggests that the Fe-intermetallic phases may act as stress raisers and crack initiation sites that reduce the strength and ductility. By reason that experimental alloy contains less than $0.108 \%$ of $\mathrm{Fe}$ and $0.007 \mathrm{Mn}$, compact skeleton-like $\mathrm{Al}_{15}(\mathrm{FeMn})_{3} \mathrm{Si}_{2}$ phase and very short and little $\mathrm{Al}_{5} \mathrm{FeSi}$ needles were present. During heat treatment compact Fe-phase dissolved and fragmented to smaller skeleton particles. Long platelets $\mathrm{Al}_{5} \mathrm{FeSi}$ phases were shortening and narrowing into small needles phases. These results are in satisfactory agreement with $[11,29]$.

\subsection{Mechanical properties}

Alloys of the A356 type (AlSi7Mg0.3) are usually heat treated in order to develop higher mechanical properties. Heat treatment of Al-Si-Mg alloy causes precipitation hardening, spheroidization of silicon particles, increased bonding between the hard second phase silicon particles and aluminium. Magnesium's role is to strengthen and harden aluminium castings. Silicon combines with magnesium is about to form the hardening phase, $\mathrm{Mg}_{2} \mathrm{Si}$ that provides the strengthening of this alloy. According to the increase of the strength, the hardness is also improved.

The effect of experimental heat treatment on mechanical properties of the AlSi7Mg0.3 manufactured cylinder heads castings shows Fig. 7. Utility ultimate tensile strength (UTS) and hardness (HBS) of all heat treated specimens increase with solution treatment time at $530^{\circ} \mathrm{C}$. Elongation (ductility) with solution treatment time decreases. The trend of increase in UTS and decrease in elongation observed in this study is in good agreement with other researcher [12, 17, 21-22, 27-28, 30-31].

The required mechanical properties used in manufacture for a typical aluminium cylinder head castings OM 661 for Daewoo includes an ultimate tensile strength of 245 $\mathrm{MPa}$, Brinell hardness of $80 \mathrm{HBW}$ and ductility of $6 \%$. These values meet more or less all experimental heat treated samples.

Ultimate tensile strength in as-cast state was measured approx. $192 \mathrm{MPa}$ (Fig. 7a). With a solution time of 2 and 3 hours at $530^{\circ} \mathrm{C}$, the UTS were substantially higher (approx. 236 and $250 \mathrm{MPa}$ ) than those obtained from the as-cast specimens, but they are still clearly lower than the values that could be achieved with a longer solution time. By increasing solution time from 2 to 4 hours, the UTS increased to $264 \mathrm{MPa}$. With further increase of the solution time up to 5 hours, the UTS increased to $268 \mathrm{MPa}$. With a prolonged solution 
treatment time of 6 or 7 hours at $530^{\circ} \mathrm{C}$, the UTS achieved were 284.5 and $297 \mathrm{MPa}$ respectively. This means that with a relatively short solution treatment time of 3 hours, more than $100 \%$ of the maximum UTS can be achieved.
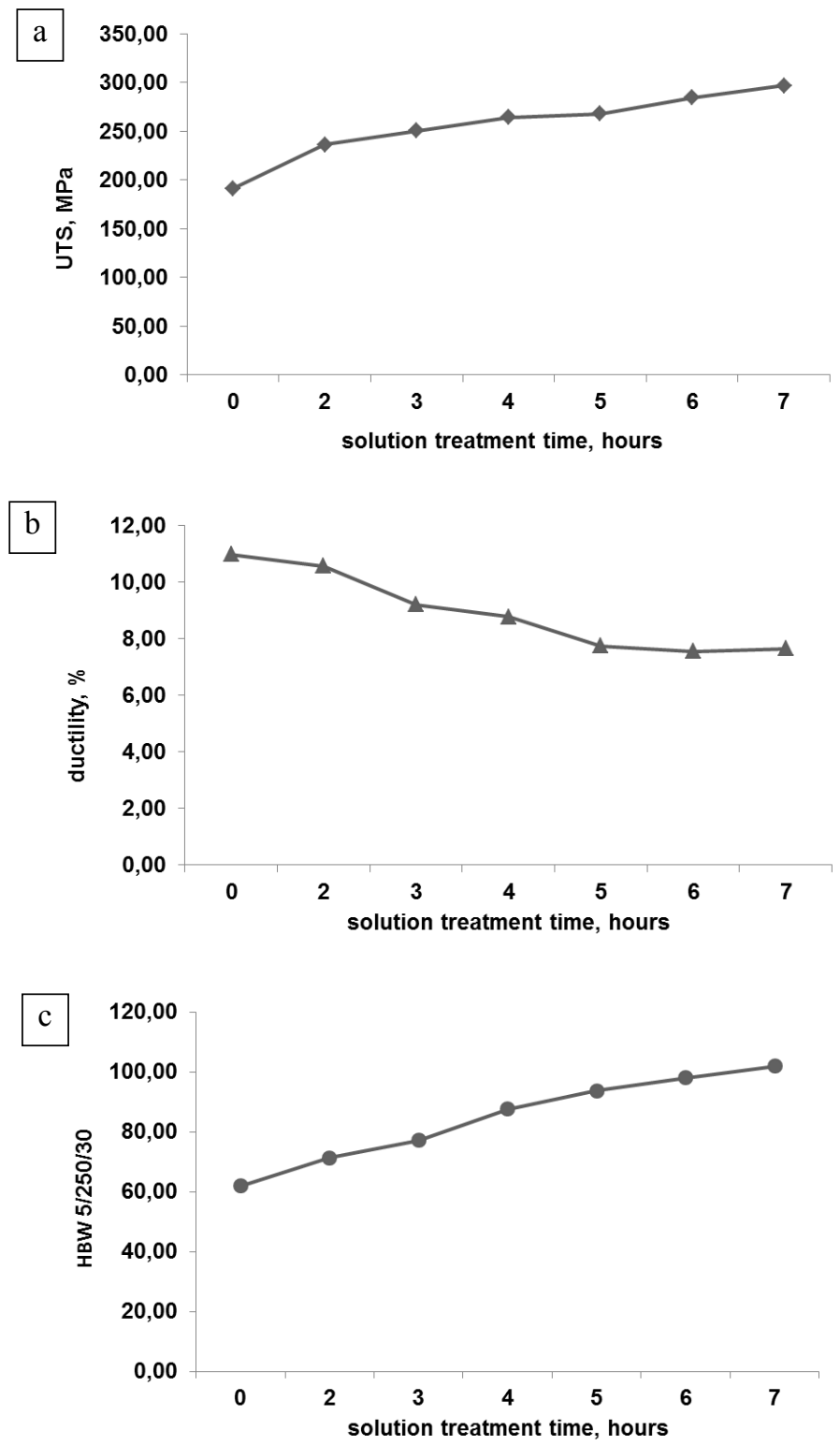

Fig. 7. Effect of solution treatment on mechanical properties:

a) UTS; b) ductility; c) Brinell hardness

The eutectic Si particles also strengthen the alloy. For the same amount of Si, smaller and more uniformly distributed particles have a stronger effect. The fragmentation of $\mathrm{Si}$ fibres reduces the particle size and increases the particle number and thus strengthens the alloy. The fragmentation of the eutectic Si takes place mostly at the early stage of solution treatment, and so, the strengthening effect caused by the morphology variation of $\mathrm{Si}$ 
particles occurs mostly in this time. The Si fragmentation still may be occurring, but slowly, and at the same time, Si particles are spheroidized and coarsened. In this time, the strengthening effect caused by Si fragmentation is counteracted by the weakening effects of coarsening and spheroidization, resulting in small variations in strength.

In Fig. $7 b$ the ductility to fracture is seen to decrease with ageing time as the ultimate tensile strength increases.

Effect of solution treatment time at $530^{\circ} \mathrm{C}$ on hardness shows Fig. $7 \mathrm{c}$. Brinell hardness in as-cast state was approx. $62 \mathrm{HBW} 5 / 250 / 30$ (Fig. 7c). With a solution time of 2 hours the HBW were higher more than $15 \%(71.3 \mathrm{HBW})$. By increasing solution time from 2 to 3 or 4 hours, the HBW increased to 77.2 (grow about $24.5 \%$ ) and 87.7 HBW (41\%) respectively. With further increase of the solution time up to 5 hours, the HBW increased to 93.8 (more about $51.2 \%$ as in as-cast state). With a prolonged solution treatment time of 7 hours at $530^{\circ} \mathrm{C}$, the $\mathrm{HBW}$ were 102 . Regularly hardness increased after experimental heat treatment. It is well-known that the $\mathrm{Si}$ phase is harder than Al-phase. Hence, the size, morphology and distribution of Si could affect the hardness of Al-Si alloy. Moreover, finer Si provides more obstacles to grain boundary sliding. Therefore, the treated alloys which have finer Si-particles in structure present higher hardness values.

\section{Conclusions}

The experimental heat treatment (T6 - solution heat treatment from 2 hours to 7 hours at $530^{\circ} \mathrm{C}$, quenching in water at $20^{\circ} \mathrm{C}$ and precipitation hardening for 4 hours at $160^{\circ} \mathrm{C}$ ) improves microstructure and mechanical properties of all samples of the cylinder head casts from AlSi7Mg0.3 (A356) alloy.

The results obtained suggest that it is possible to shorten the holding time at a temperature of solution treatment.

The mechanical properties of the cylinder head castings (OM 661 for Daewoo) are reliably achieved by the manufacturer in the following heat treatment: 4 hours at $530^{\circ} \mathrm{C}$, quenching in water at $20^{\circ} \mathrm{C}$ and precipitation hardening for 4 hours at $160^{\circ} \mathrm{C}$. In this heat treatment, castings have an ultimate tensile strength $264 \mathrm{MPa}$, ductility $8.8 \%$ and Brinell hardness $87.7 \mathrm{HBW}$.

Solution temperature $530^{\circ} \mathrm{C}$ and 4 hours solution time is appropriate to obtain better Simorphology and distribution of Si particles in microstructure of the cylinder heads casts. Solution treatment blunts the sharp edges of Si particles and promotes fracture resistance. Prolonged solution treatment (more than 5 hours) leads to a coarsening of the Si particles, while the numerical Si density decreases. As the particle density decreases, a fewer number of sites are available for crack nucleation, and hence, the fracture properties are improved.

The data obtained from this study will be used to improve process control and to help the selection of the heat treatment for future products.

The authors acknowledge the financial support of the project VEGA No 1/0533/15 and European Union - the Project ITMS: 26220220154.

\section{References}

1. EAA - European Aluminium Association. The Aluminium Automobile Manual: Applications - Power train - Cylinder heads (2011)

2. ASM Handbook, vol. 15 - Casting. (ASM International, Materials Park, Ohio, USA, 2002) 
3. W. S. Miller, L. Zhuang, J. Bottema, A. J. Wittebrood, P. de Smet, A. Haszler, A. Vieregge, Recent development in aluminium alloys for the automotive industry. Materials Science and Engineering A 280, 37-49 (2000)

4. R. Molina, P. Amalberto, M. Rosso, Mechanical characterization of aluminium alloys for high temperature applications. Part1: Al-Si-Cu alloys. Metallurgical Science and Technology 29, 1, 5-15 (2011)

5. L. Heusler, F.J. Feikus, M.O. Otte, Alloy and Casting Process Optimization for Engine Block Application. AFS Transactions 01-050, 1-9 (2001)

6. E. Tillová, M. Chalupová, Structural analysis (Štruktúrna analýza), (EDIS ZU, 2009)

7. COMALCO: Modification of foundry Al-Si alloys. Technical report, No4, (Comalco Aluminum Limited. Brisbane, Australia, 1997)

8. J. Cais, J. Svobodová, V. Weiss, Influence of modification and heat treatment on the mechanical properties of the AlSi7Mg0.3 alloy. Cluster - Casting - Future: international scientific conference. Rzeszów, 67-70, (2014)

9. N. Náprstková, S. Kusmierczak, J. Cais, Modification of AlSi7Mg0.3 alloy by strontium. Manufacturing Technology 13 (3), 373-380 (2013)

10. B. Zhang, M. Garro, C. Tagliano, Dendrite arm spacing in aluminium alloy cylinder heads produced by gravity semi-permanent mold. Metallurgical Science and Technology 21 (1), 1-9 (2003)

11. E. Tillová, M. Chalupová, L. Hurtalová, Evolution of Phases in a Recycled Al-Si Cast Alloy During Solution Treatment. Scanning Electron Microscopy, Dr. Viacheslav Kazmiruk (Ed.), InTech, (2012)

12. L. Hurtalová, J. Belan, E. Tillová, M. Chalupová, Changes in structural characteristics of hypoeutectic Al-Si cast alloy after age hardening. Journal Materials Science / Medžiagotyra 18 (3), 228-233 (2012)

13. J. A. Taylor, Iron-containing intermetallic phases in Al-Si based casting alloys. Procedia Materials Science 1, 19-33 (2012)

14. K. L. Fan, G. Q. He, X. S. Liu, B. Liu, M. She, Y. L. Yuan, Y. Yang, Q. Lu, Tensile and fatigue properties of gravity casting aluminum alloys for engine cylinder heads. Materials Science and Engineering A 586, 78-85 (2013)

15. M. A. Moustafa, F. H. Samuel, H. W. Doty, Effect of solution heat treatment and additives on the microstructure of Al-Si (A413.1) automotive alloys. Journal of Materials Science 38, 4507-4522 (2003)

16. F. Paray, J. E. Gruzlesky, Microstructure - mechanical property relationships in 356 alloy. Cast Metals 7 (1), 29- 40 (1994)

17. E. Sjölander, S. Seifeddine, The heat treatment of Al-Si-Cu-Mg casting alloys. Journal of Materials Processing Technology 210, 1249-1259 (2010)

18. E. Tillová, M. Chalupová, L. Hurtalová L., E. Duriniková, Quality control of microstructure in recycled Al-Si cast alloys. Manufacturing Technology 11, 70-76 (2011)

19. ASM Metals Handbook. Vol.4 - Heat treating, (ASM International, Materials Park, OH, USA, 1991)

20. A. Manente, G. Timelli, Optimizing the heat treatment process of cast aluminium alloys. Recent Trends in Processing and Degradation of Aluminium Alloys, (InTech, 2011) 
21. S. Shivkumar, S. Ricci, C. Keller, D. Apelian, Effect of solution treatment parameters on tensile properties of cast aluminum alloys. Journal of Heat Treating 8 (1), 63-70 (1990)

22. M. Tash, F. H. Samuel, F. Mucciardi, H. W. Doty, Effect of metallurgical parameters on the hardness and microstructural characterization of as-cast and heat-treated 356 and 319 aluminum alloys. Materials Science and Engineering A 443, 185-201 (2007)

23. L. Hurtalová, E. Tillová, M. Chalupová, The changes of fatigue properties in aluminium cast alloy during solution treatment. Key Engineering Materials 592-593, 433-436 (2014)

24. S. Capuzzi, Development of heat treatments for automotive components die cast with secondary aluminium alloy at semi-solid state. Metallurgia Italiana 106 (3), 3-11 (2014)

25. M. Javidani, D. Larouche, X. Grant Chen, Dissolution of $\mathrm{Cu} / \mathrm{Mg}$ bearing intermetallics in Al-Si foundry alloys. Metallurgical and Materials Transactions A: Physical Metallurgy and Materials Science, 47 (10), 4818-4830 (2016)

26. H. C. Long, J. H. Chen, C. H. Liu, D. Z. Li, Y. Y. Li, The negative effect of solution treatment on the age hardening of A356 alloy. Materials Science and Engineering A 566, 112-118 (2013)

27. D. L. Zhang, L. H. Zheng, D. H. StJohn, Effect of a short solution treatment time on microstructure and mechanical properties of modified Al-7wt.\%Si-0.3wt.\%Mg alloy. Journal of Light Metals 2, 27-36 (2002)

28. D. Lados, D. Apelian, L. Wang, Solution Treatment Effects on Microstructure and Mechanical Properties of Al-(1 to 13 pct $)$ Si-Mg Cast Alloys. Metallurgical and Materials Transactions B 42B, 171-180 (2011)

29. L. Richtárech, D. Bolibruchová, E. Kucharčíková, Appliciation of heat treatment for elimination of iron in secondary Al-Si alloy. Manufacturing Technology 16 (2), 431436 (2016)

30. D. Lados, D. Apelian, L. Wang, Aging Effects on Heat Treatment Response and Mechanical Properties of Al-(1 to 13 pct $) S i-M g$ Cast Alloys. Metallurgical and Materials Transactions B 42B, 181-188 (2011)

31. M. Sága, P. Kopas, M. Uhríčik, Modeling and Experimental Analysis of the Aluminium Alloy Fatigue Damage in the case of Bending - Torsion Loading. Procedia Engineering 48, 599-606 (2012) 